\title{
Music's Invisible Drive in Brand Marketing of Liquor Advertisement
}

\author{
Liao Qinfang ${ }^{1^{*}}$, Yan Ming ${ }^{2}$ \\ ${ }^{I}$ Sichuan University of Science and Engineering, Sichuan, China \\ ${ }^{2}$ Nanchen Jingxiu, No.3,Kehua South Road, Wuhou district, Chengdu, Sichuan, China
}

*Corresponding Author: Liao Qinfang, Sichuan University of Science and Engineering Sichuan, China

\begin{abstract}
Music is an imaginative and appealing means of expression, which plays an increasingly important role in modern brand marketing. In the process of high development of commodity economy and modern humanistic environment, advertising has become the most important means of brand marketing. Hence, music, as a special product of advertising, refers to music used by mass media in the process of advertising. It not only has the aesthetic characteristics of music art, but also contains the characteristics of advertising art. Music plays an important role in the invisible promotion of different liquor advertisements in China and the west.
\end{abstract}

Keywords: Liquor Advertisement, Brand Marketing, Drive, Music

\section{Classification and Characteristics of Advertising Music}

Music in TV advertisements is generally divided into two categories, one is called accompaniment music, also known as background music, often instrumental works; The other is called a jingle, or foreground music, which is usually performed vocally.

\section{ACCOMPANiment Music}

The selection of accompaniment music mainly depends on the plot, atmosphere, character characteristics and plot development in TV advertisements, which can make the plot of advertisements more and more vivid and effectively render the theme of advertisements. The accompaniment music in the advertisement includes classical music, light music and folk music. Classical music is a classic work that has gone through the selection and precipitation of time. It can show implicit, delicate and dignified emotions. If similar emotions need to be shown in advertisements, classical music is of course the first choice for accompaniment music. The structure of light music is simple, the rhythm stretch and bright, the melody beautiful, generally played by the violin or piano. Relaxed and lively is its main characteristic, which can build the emotional appeal that gives romantic warmth. Folk music is rich in strong local characteristics and national characteristics, and is widely used in the advertising of products with national and local characteristics. ${ }^{[1]}$

As TV advertisement music is a kind of brand marketing art, accompaniment music has a high degree of abstractness, generalization and image. What it shows is an abstract artistic conception, and it guides the audience's emotion emotionally, thus subtly influencing the audience's understanding of the advertising content. ${ }^{[2]}$ In addition, another important feature of accompaniment music is that it has a high degree of recognition, and people have a very deep memory of music. When people are familiar with the words and music of a piece of music, then when this specific music appears in the advertisement, the product of the advertisement will automatically emerge in their mind. The television advertisement just took advantage of this important characteristic of advertisement music.

\section{ADVERTISING SONGS}

Unlike the background music, advertisement songs are generally just simple instrumental music works, while advertisement songs are all vocal music works. The perfect combination of lyrics and melody is used to "sing" the name of the product or the words to introduce the product, and catchy, so as to increase the audience's impression of the product. 
Advertising songs are created according to different marketing objectives, so there are different types, which can be roughly divided into the following three categories:

\subsection{Original Type}

According to the nature of the commodity, as well as the image and plot to be presented by the advertisement to create, the lyrics are generally the name of the commodity in order to be the biggest selling point of the commodity. At the same time with a simple-and-easy-to-remember melody, it is easy to spread. In addition, it is necessary to coordinate the lyrics and melody, and try to avoid homophonic or homophonic phenomenon lest the audience will have a misunderstanding of the meaning of the lyrics. ${ }^{[3]}$ For example, in the advertisement of tuopai qujiu, a very simple melody is used to match with the lyrics of "Youyou suiyuejiu, didi Tuopai( Chinese pinyin)(long and long years and months of time, drops and drops of Tuopai feeling )(author translated)". Although it is only a simple sentence, it is full of vitality and contains a sense of the vicissitudes of history. It is like a strong aroma of wine, which triggers the taste experience of the audience. As a result of the "Tuopai Qujiu", this widely spread advertising song, the market sales of Tuopai Qujiu increased significantly.

\subsection{Adapted Popular Songs}

Nowadays the characteristic of popular songs is that its melody has been familiar to people and become a household name. The lyrics of such songs can be refilled or modified, which enables people to quickly connect the known popular songs with new products, thus eliminating the sense of strangeness and distance to the products. For example, the popular jelly brand "STRONG" is adapted from the children's song "Old Macdonald had a farm" which is very familiar to children and their parents. Therefore, the STRONG jelly is known to the people all over the country, and whenever people hear the children's song, people cannot help thinking of the first product STRONG jelly.

\subsection{Direct Reference to the Famous Songs}

There is another type that directly refers to the part or all of the original song for advertising publicity. Such advertisements usually take advantage of the similarity or common ground between the original song and the advertising products. For example, the songs describe the place where the products are made, or the situations depicted by the songs are the visual transmission effects required by the advertising plots. ${ }^{[4]}$ For example, A Native Of Beijing In New York by Kongfu family wine is in line with the situation of family reunion expressed by Kongfu family wine. In addition, in the 1990s, Luzhou Laojiao decided to invite Zhou Huajian to be the image spokesman of Tequ Laojiu and took Zhou Huajian's famous song "Friends" as the background music of the advertisement, implying that wine, like friends, will become all the more mellow as time goes on. This old song has been widely circulated for many years, and it can be used again in this advertisement, which can arouse people's memories and deepen their impression and favorable impression of the brand.

\section{The Role OF AdVERTISING MUSiC}

- In the 1970s, T. Schwartz, a famous American advertising theory expert, proposed the "resonance model", which could well explain the role of music in brand communication. He believed that the brain wave generated by the stimulation of cerebral cortex by music would prompt the brain to stop or continue to receive this stimulation. If this stimulation is positive, the audience would often produce "music memory". ${ }^{[5]}$ Therefore, advertising music can trigger deep memories of the audience and arouse their emotional experience, especially positive emotional experience. When the audience's experience is consistent with the advertisement, it will trigger migration association and generate emotional resonance. Music makes the audience feel "both sad and happy", and this emotional resonance can shorten the psychological distance between the brand and consumers, thus forming the resonance of the brand.

- Music can eliminate the dissonant visual and auditory factors in advertisements, connect and separate the isolated visual scenes, and enhance the memory of visual content, such as product logo and product design. ${ }^{[6]}$ The visual effect of an advertisement is usually composed of multiple images cut and put together, and each of the images and scenes has its own sound, hence the background music can play a role of a good connection, make a picture scene naturally transited to the next, like an ancient picture scroll, and push the patterns of seemingly independent but inner- related together. 


\section{Comparison OF MUSIC BeTWEen CHINESE AND WESTERn AdVERTISEMENTS}

Advertising music is an art, and art is a carrier of local culture, so the advertising music in China and the west also reflects the completely different cultural traditions in China and the west. Chinese culture regards freehand brushwork as the highest literary pursuit. From classical ancient poetry to elegant landscape painting and vigorous calligraphy works, all of them emphasize the importance of artistic conception. Western culture, on the other hand, is good at storytelling and emphasizes realism. From the world classic masterpiece The Bible, to each period of different styles of literary works, they all have confirmed this cultural characteristic. ${ }^{[7]}$

In China, people make good use of beautiful pictures and beautiful music to create a blend of scenes for the audience, and sincerely express their feelings, so that the audience can enjoy the beauty, and then have a trust in and a good impression on the goods. Because there is the need to cooperate with the beautiful picture, so the advertising music generally uses lyric accompaniment music. From start to finish this background music, has almost rarely rich level performance, no twists and turns, pause, and is only slow and easy. ${ }^{[8]}$ For example, many Chinese liquor ads, such as Maotai liquor, Wuliangye liquor, Xi liquor, Gong liquor etc., show the pictures of China palaces, liquor cellars, scrolls with the background music of Chinese national characteristics, to create a majestic and elegant artistic vision, then come the liquor brand names gradually, with a male voice reading out the characteristics and names of liquors, such as " flavor, classic, sauce, share a better future, Xi liquor, sauce ,1988", "Old, history; Old, inheritance; Old, trust; Luzhou Laojiao passes on classics, with a century-old sauce, Laoluzhou", " Fame family model, elegance and outstanding in the world; once taste, fine essence of five grains; sublimation value, the supremacy of liquor and the most true, the treasure class of five grains liquor. (名门典范, 优雅卓然于世, 品味间, 五粮声华凝萃, 升华价值, 至醇至真, 珍品级五粮醇)"

Western advertising is more narrative, and has a sense of humor, so advertising music relatively has the narrative function. In order to achieve this function, acoustics, human voice, synchronous sound as a variety of sound elements are highly used, and dramatic sound quality is employed more, to stimulate the audience's hearing in a full range, make advertising music better-foiled and the story well-presented and let the advertising unexpected and unforgettable. ${ }^{[9]}$ For example, Vitoria Beer in Australia once had a very creative advertisement. The advertising at the beginning of the scene is a middle-aged man with his side facing the camera. He takes a deep breath of relief, and then firmly walks towards a door. In the second scene of an overlooking from above, what the man is walking into is a concert hall. A third lens zoom in and see a man through a group of music band members, who comes to the podium in the center of the stage, takes up the command bar, ready to start command. The story comes at this point, that the audience subconsciously think next it should be the band members who prepare their own instruments to play, but it is unexpected that all members take up beer bottles as "instrument", there will be single or multiple beer bottles used as "wind" of similar clarinet, oboe, mallet and wooden tapping on a different part of the bottle as the" percussion instruments", and the bottle falling high up down to the face of the drum, as the "drumstick", all these done at one fling, the whole music chapter composed of the beer bottles as instruments of music very sweet, and terrific. In the last scene, the conductor is very satisfied with the "performance" just now, laughing heartily at the orchestra members, which is in sharp contrast to the deep breath at the beginning. On one side, next, is the emergence of the beer's trademark. It is so impressive.

\section{CONCLUSiON}

In conclusion, we can find that both the accompaniment of music and the advertising songs of music play an important role in promoting the brand marketing of alcohol advertisements in China and the west. Music can eliminate the dissonant auditory factors, make the scene conversion more smooth and natural, and enable the audience to evoke emotional experience and emotional resonance.

\section{REFERENCES}

[1] Xu Hong, Xiao Shasha, Music and TV advertising, current media, 2004, 4.

[2] Chen Yicheng, TV music and audio. Beijing: China radio and television press, 2004.

[3] Huang Maojun, The communication strategy of music sound in TV advertising, Contemporary Tv, $2013,7$.

[4] Liao Bingyi, The art of radio and television advertising. Shanghai: Shanghai foreign language education publishing house, 2006. 
[5] S. Haeckel, The influence of music on advertising [J]. Psychology and marketing, 1984, 1.

[6] Jin Liyin, The role of music in marketing context, contemporary finance and economics, 2005, 12.

[7] Wang Yifan, The influence of advertising music on audience's brand recognition and communication [J]. Journal of Heihe University, 2016, 7.

[8] Huang Lu, On the performance of music in TV advertising, Friends of science, 2010, 5.

[9] Zhang Junjie, Liu Wenhua. A brief analysis of the psychological effect of advertising music on consumers [J]. Popular literature and art, 2012, 8.

\section{AUTHORS' BIOGRAPHY}

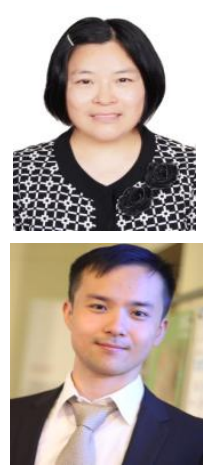

Liao Qinfang, born in Zigong in Nov. 1964, female, Han nationality, Master of Arts, associate professor, Sichuan university of Science and Engineering, 643000

Yan Ming, born in Zigong in Oct. 1989, male, Han nationality, Master of Arts, graduated from Estonian national music college in June 2016, majoring in piano performance.

Citation: Liao Qinfang, Yan Ming. "Music's Invisible Drive in Brand Marketing of Liquor Advertisement". International Journal of Humanities Social Sciences and Education (IJHSSE), vol 6, no. 3, 2019, pp. 123-126 doi: http://dx.doi.org/10.20431/2349-0381.0603014.

Copyright: (C) 2019 Authors. This is an open-access article distributed under the terms of the Creative Commons Attribution License, which permits unrestricted use, distribution, and reproduction in any medium, provided the original author and source are credited. 